\title{
Effects of Repeated Treatment with MDMA on Working Memory and Behavioural Flexibility in Mice
}

\begin{abstract}
Xavier Viñals ${ }^{1}$, Rafael Maldonado ${ }^{1}$ and Patricia Robledo ${ }^{1,2}$
${ }^{1}$ Laboratory of Neuropharmacology, Pompeu Fabra University (UPF), Barcelona, Spain

${ }^{2}$ Neuropsychopharmacology Research Program, IMIM (Hospital del Mar Research Institute), PRBB, Barcelona, Spain.
\end{abstract}

Corresponding Author:

Patricia Robledo

Neuropsychopharmacology Research Program

IMIM (Hospital del Mar Research Institute)

PRBB

Calle Dr. Aiguader, 88

08003 Barcelona

SPAIN

Tel: + 349331608

FAX: + 34933160901

Email: probledo@imim.es

Running Head: MDMA and cognitive flexibility 


\section{Abstract}

Cognitive deficits have been observed in chronic 3, 4methylenedioxymethamphetamine (MDMA) users, although it is still not clear which specific sub-sets of executive functioning are impaired. We evaluated the effects of MDMA (0, 3 and $30 \mathrm{mg} / \mathrm{kg}$, twice daily during 4 days) on working memory, impulsivity and behavioural flexibility in mice, and changes in extracellular levels of dopamine (DA) in the striatum. Daily treatment with the high dose of MDMA (30 $\mathrm{mg} / \mathrm{kg}$ ) disrupted performance of an acquired operant alternation task, and this impairment was still apparent 5 days after the last drug administration. Decreased alternation was not related to anhedonia since no differences were observed between groups in the saccharine preference test under similar experimental conditions. Correct responding on delayed alternation was increased one day after repeated treatment with MDMA (30 mg/kg), probably due to general behavioural quiescence. Notably, the high dose regimen of MDMA impaired set-shifting related to an increase in total perseveration errors. Finally, basal extracellular levels of DA in the striatum were not modified in mice repeatedly treated with MDMA with respect to controls. However, an acute challenge with MDMA (10 mg/kg) failed to increase DA outflow of mice receiving the highest MDMA dose $(30 \mathrm{mg} / \mathrm{kg}$ ), corroborating a decrease in the functionality of dopamine transporters. Seven days after this treatment, the effects of MDMA on DA outflow were recovered. These results suggest that repeated neurotoxic doses of MDMA in mice produce lasting impairments in recall of a working memory task and reduce cognitive flexibility.

Keywords: delayed alternation, executive functions, set-shifting, saccharine intake, dopamine, microdialysis 


\section{Introduction}

Chronic administrations of most drugs of abuse induces profound neuroadaptations in brain reward circuits, and brain areas involved in cognitive processing, which contribute to the development of drug addiction (see Koob and Volkow, 2010 for review). Indeed, some of the hallmarks of addiction such as loss of control over drug-taking and compulsive drug-seeking point to abnormal executive functioning related to response inhibition and behavioural flexibility (see Winstanley et al., 2010 for review). However, human research investigating the effects of chronic drug intake on specific sub-modalities of central executive processing has been difficult partly due to the confounding problems of poly-drug abuse, and/or pre-existing psychopathology. This is particularly the case for studies in consumers of $( \pm)-3,4-$ methylenedioxymethamphetamine (MDMA, ecstasy), who often show concomitant use of other substances including cocaine, amphetamine, alcohol, tobacco, LSD, cannabis, and opioids (Gouzoulis-Mayfrank and Daumann, 2006). Thus, although deficits in working memory and/or impulsivity have been observed in chronic ecstasy users (Quednow et al., 2007; Von Geusau et al., 2004; Wareing et al., 2004; Dafters, 2006; Bhattachary and Powell, 2001; Kalechstein et al., 2007), other studies have found mixed results (Fox, Parrot, Turner, 2001; Fox et al., 2002; Clark et al., 2009; Hanson, Luciana, Sullwold, 2008; Hanson and Luciana, 2010). One explanation for the lack of clear-cut effects may be the relative contribution to cognitive impairment produced by the various substances that are co-abused by the subjects included in each study (de Sola Llopis et al., 2008; Verdejo-Garcia et al., 2005). In this sense, studies in naive laboratory animals can be advantageous to overcome these confounding factors. 
Deficits in learning and memory have been reported in rats and monkeys following acute (Frederick and Paule, 1997; Able et al., 2006), and repeated administration of MDMA (Dalley et al., 2007; Schenk, Harper, Do, 2010). However, despite the fact that MDMA produces serotonergic depletion in these species (Ricaurte et al., 1988; Mayerhofer, Kovar, Schmidt, 2001; Colado, O’Shea, Green, 2004), a clear relationship between serotonergic neurotoxicity and the cognitive impairments produced by MDMA has not always been established (see Baumann, Wang, Rothman, 2007 for review). In mice, previous studies have demonstrated that high doses of MDMA administered in a binge-pattern, producing striatal dopaminergic neurotoxicity, induce learning and recall deficits of an active avoidance task (Trigo et al., 2008), and increase the resistance to extinction of instrumental responding when food reward is no longer available (Plaza-Zabala et al., 2010). These results demonstrated that MDMAinduced dopaminergic neurotoxicity alters learning and memory processes in mice, and implied deficits in central inhibitory control. In order to understand whether neurotoxic doses of MDMA affect specific sub-sets of executive function such as impulsivity and behavioural flexibility, we evaluated the effects of a repeated dosing regimen of MDMA on the ability of mice to inhibit premature responding in an operant delayed alternation task (Weiss s et al., 2005), and to perform an operant set-shifting task (Enomoto, Tse, Floresco, 2011). Finally, we measured dopamine (DA) levels in the striatum of mice after MDMA treatment using in vivo microdialysis. 


\section{Materials and Methods}

\section{Animals}

Male C57BL/6J mice (Charles-River, France) weighing approximately $24 \mathrm{~g}$ at the beginning of the experiment were individually housed in standard laboratory cages and temperature-controlled conditions: room temperature of $21 \pm 2^{\circ} \mathrm{C}$, humidity of $40 \%$ to $50 \%$, and a reversed 12-h light/dark cycle (lights on at 20:00, off at 8:00). Behavioural testing was performed during the dark phase of the light/dark cycle. All experimental procedures were approved by the local ethical committee (CEEA-PRBB), and met the guidelines of the local (Catalan law 5/1995 and Decrees 214/97, 32/2007) and European regulations (EU directives 86/609 and 2001-486). Our laboratory has the Statement of Compliance with Standards for Use of Laboratory Animals by Foreign Institutions (\#A5388-01); approved by the Office of Laboratory Animal welfare (OLAW) on 06/08/2009 (expires on 06/30/2014).

\section{Drug treatment}

MDMA hydrochloride was obtained from Lipomed, A.G. (Arlesheim, Suisse) and dissolved in $0.9 \%$ sodium chloride. Mice were treated with MDMA (3 and 30 $\mathrm{mg} / \mathrm{kg}$, i.p. $)$ or with saline $(0.1 \mathrm{ml} / 10 \mathrm{~g})$ twice daily every $4 \mathrm{~h}$ during 4 days.

\section{Delayed Alternation Task}

Animals were first food deprived to $85-90 \%$ of their free-feeding weight (water was supplied ad libitum), and then trained in an operant delayed alternation task. The experiments were conducted in 5 mouse operant chambers (Med Associates Inc. Georgia, VT, USA) housed in sound-attenuated boxes equipped with a fan to supply ventilation and avoid ambient noise. The chambers were comprised of a house-light, 2 
nose poking holes $(15 \mathrm{~mm}$ diameter) equidistantly placed on one of the walls, and a food magazine placed on the opposite wall, where $20 \mathrm{mg}$ chocolate-flavoured pellets (AIN-76A Rodent Tab Choc. Testdiet, Richmond, IN, USA) were delivered. The nose pokes and the magazine were equipped with infrared photocells and lights, and responses were recorded by the computer using the MED-PC software (Med Associates Inc. Georgia, VT, USA). Mice were trained daily for either $30 \mathrm{~min}$ or until 50 reinforcers were delivered. Animals were then returned to their home-cages and fed with standard chow (approximately 2-3 g each). Shaping begun with mice receiving food pellets from the magazine every $30 \mathrm{sec}$ during 3 sessions. Then they were trained to respond on either nose poke to obtain a food pellet on a continuous reinforcement schedule. During the third step, mice were reinforced for nose-poking only on the left or the right hole during 4 consecutive sessions, switching the active nose poke between sessions. Subsequently, the alternation procedure started, where a choice opportunity was signalled by illumination of the house-light. After the first response in one of the nose-pokes, the house-light was extinguished, the magazine-light was turned on, a food pellet was delivered, and a sound was presented during $1 \mathrm{sec}$. If the mouse collected the pellet, the house light was illuminated after a fixed delay and the next trial begun. If the mouse responded in either of the nose pokes during the delay interval, or in the incorrect nose poke, the house-light was extinguished and the food cup light was illuminated, but no food was presented nor the sound activated. The mouse was then required to insert its nose into the magazine to restart another trial. Initially, the delay interval was short $(1 \mathrm{sec})$, so the mouse simply learned to distribute responses between alternate locations. The criteria for acquisition of the alternation task was 1) a minimum of 40 reinforcers obtained per session; 2) more than $75 \%$ of correct responding 3) stability of responding during 2 consecutive sessions with less than $20 \%$ deviation from 
the mean. In the delayed alternation test, four different delay intervals were used $(2,4,6$ and $8 \mathrm{sec}$ ), presented in a pseudorandom order. Each delay was presented until a correct response was made, and the daily sessions were terminated when each delay was correctly completed for a total of 10 trials. The test was performed during 7 consecutive days. The ratio of correct responses was determined during the alternation procedure, as well as in the delayed alternation.

Three different experiments were performed using this procedure. In experiment 1, the acute effects of MDMA were evaluated on a previously learned alternation task. Once the established criteria for acquisition of operant alternation were achieved, mice were treated twice daily with MDMA or saline during 4 days. Behavioural testing was conducted during 4 consecutive days, $19 \mathrm{~h}$ after the last MDMA administration, and always before the next MDMA treatment. This procedure avoided possible MDMAinduced hyperlocomotor effects that could interfere with operant performance. Testing was continued for another 7 days after treatment. In experiment 2 , the effects of repeated treatment with MDMA on learning a novel operant alternation task were evaluated. Mice were treated with MDMA or saline twice a day during four days, and on day 5 they were trained on the alternation procedure for 7 days. In experiment 3 , mice were trained to alternate responses between two nose-pokes until meeting criteria before being treated with MDMA or saline twice daily during 4 days. The next day, all the animals were tested in the delayed alternation procedure during 7 consecutive days.

\section{Set-Shifting procedure}

Animals were first food deprived to $85-90 \%$ of their free-feeding weight. The operant chambers (Med Associates Inc. Georgia, VT, USA) were comprised of a houselight, 2 retractable levers, two light cues which were placed above the levers and a food 
magazine placed between both levers, where $20 \mathrm{mg}$ of food pellets (Testdiet, Richmond, IN, USA) were delivered. Sessions were performed daily for $30 \mathrm{~min}$, and mice were then returned to their home-cages and fed standard chow (approximately $2-3 \mathrm{~g}$ each). Shaping begun with mice receiving food pellets into the magazine every 30 sec during 3 sessions, and during 3 additional days mice were trained to respond on either lever on a continuous reinforcement schedule. During the visual-cue discrimination task, mice were trained to press the lever that had a cue-light illuminated above it on a fixed ratio 3 (FR3) schedule of reinforcement. After each trial, the cue-light was extinguished and both levers were retracted for an inter-trial interval (ITI) of $5 \mathrm{sec}$. Sessions consisted of 3 10-min blocks, with the right and left cue-lights being illuminated during half of the trials. Mice were trained in this procedure until they met criteria of more than $80 \%$ of correct responses in at least 2 out of the 3 blocks per session during two consecutive days. After achieving criteria, mice received MDMA or saline twice daily during 4 consecutive days. The day after treatment, visual-cue discrimination retention was tested during 2 consecutive days, and on the third day after the treatment, a set-shift was introduced. Thus, animals had to stop using a respond-to-cue light strategy and use a respond-to-position strategy irrespective of the cue-light location. Sessions consisted of 3 10-min blocks, with the active left and active right levers counterbalanced between animals. The type of errors considered were: "perseveration errors", when mice pressed the inactive lever with the cue-light on, and "never reinforced errors", when mice pressed the inactive lever with the cue-light off. Mice were tested using this paradigm until they met criteria of more than $80 \%$ of correct responses in at least 2 out of the 3 blocks per session during two consecutive days. Ratio of correct responses and errors to criteria (perseverant responses and never reinforced errors) were determined. 
Preference for saccharine and high-fat diet

Twelve food and drink monitoring chambers (PHECOMP, PanLab, Barcelona, Spain) were used with two different types of food (1) high fat diet with $60 \%$ calories from fat (5.21 kcal/gram) (58G9 Purified Diet, Testdiet, Richmond, IN, USA) and (2) normal diet with $12 \%$ calories from fat (3.87 kcal/gram) (58G7 Purified Diet, Testdiet, Richmond, IN, USA). Two types of liquids devoid of caloric content were also available: (1) $0.25 \%$ saccharine sweetened water and (2) normal water. Mice were food deprived during the experiment, except when placed into the chambers for $3 \mathrm{~h}$ daily with food and drink freely available. Consumption of both kinds of food and drink was recorded during this period. Baseline values were obtained after 2 weeks of habituation to the chambers in order to avoid the novelty aversion for the new kind of food or drink. After habituation, mice received either MDMA (3 and $30 \mathrm{mg} / \mathrm{kg}$ ) or saline twice daily during 4 days. The first daily injection was administered $1 \mathrm{~h}$ after the end of the recording to obtain preference values under drug-free conditions. At the end of the drug administration period, preference studies were continued for 7 additional days. Caloric intake and preference for high-fat diet and for saccharine sweetened water were determined.

Surgery and Microdialysis Procedure

Mice received MDMA or saline twice daily during 4 consecutive days, and were divided into 2 groups. In Group 1, microdialysis experiments were carried out one day after the last drug administration, and in Group 2, microdialysis was performed 7 days after the last drug administration. Guide cannulae were implanted in all mice before treatment begun. Animals were anaesthetized with a ketamine/xylazine mixture (5:1; $0.10 \mathrm{ml} / 10 \mathrm{~g}$, i.p.) and placed in a stereotaxic apparatus. Unilateral guide cannulae 
(CMA7, CMA Microdialysis, Stockholm, Sweden) were implanted vertically in the dorso-lateral striatum (AP, $+0.5 \mathrm{ML}, \pm 2.5 ; \mathrm{DV},-2.60 \mathrm{~mm}$ from bregma) (Paxinos and Franklin, 1997) and then fixed to the skull with dental cement. Three days before the experiment, analytical probes (CMA7, 1 mm, CMA Microdialysis, Stockholm, Sweden) were carefully inserted inside the guide cannulae, and two days later, animals were habituated to the microdialysis environment overnight. The following morning (first (group 1) and seventh (group 2) day after the last drug administration), probes were perfused with a ringer solution $(\mathrm{NaCl}: 148 \mathrm{mM}, \mathrm{KCl}: 2.7 \mathrm{mM}, \mathrm{CaCl} 2: 1.2 \mathrm{mM}$ and $\mathrm{MgCl}$ : $0.8 \mathrm{mM}, \mathrm{pH}$ 6.0) at a constant rate of $1 \mu \mathrm{l} / \mathrm{min}$. A period of $1 \mathrm{~h}$ was allowed for stabilization before collection of 4 baseline samples. Mice were subsequently challenged with an injection of MDMA (10 mg/kg, i.p.) and collection of samples continued for an additional period of $3 \mathrm{~h}$. Dialysates $(20 \mu \mathrm{l})$ were injected without any purification into a HPLC system that consisted of a pump linked to an automatic injector (Agilent 1100, Palo Alto, USA), a reverse-phase column (Zorbax SB C18, 5 mm, 150 x $4.6 \mathrm{~mm}$, Agilent Technologies, Palo Alto, USA), and a coulometric detector (Coulochem II, ESA Inc., Chelmsford, USA) with a 5011A analytical cell. DA was quantified as previously described (Robledo et al., 2004). Briefly, the first electrode was fixed at $-100 \mathrm{mV}$ and the second electrode at $+300 \mathrm{mV}$. The gain of the detector was set at $10 \mathrm{nA}$. The composition of the mobile phase was $50 \mathrm{mM} \mathrm{NaH} 2 \mathrm{PO} 4,0.1 \mathrm{mM}$ Na2EDTA, $0.65 \mathrm{mM}$ octyl sodium sulfate and $15 \%$ (vol/vol) methanol, $\mathrm{pH} 3.5$. The flow rate was set at $1 \mu \mathrm{l} / \mathrm{min}$ and the sensitivity of the assay was $0.2 \mathrm{pg} / 20 \mu \mathrm{l}$. At the end of the experiments, mice were sacrificed and brains cut using a cryostat. Serial coronal sections $(20 \mu \mathrm{m})$ were then processed with Cresyl Violet (Sigma-Aldrich, Madrid, Spain). Only those mice with correct probe placements were used in the study.

\section{Statistical analysis}


The data were analyzed using one or two-way repeated measures analysis of variance (ANOVA) when appropriate. Individual comparisons were carried out using the Dunnet post-hoc test. The level of significance was set at $\mathrm{p}<0.05$. 


\section{Results}

Effects of Repeated MDMA on a Previously Acquired Operant Alternation Task

The effects of repeated MDMA administration on operant alternation are shown in Figure 1. Prior to drug administration, the groups did not differ in performance $\left[F_{(2,20)}\right.$ $=0.401(\mathrm{NS})]$. However, during drug treatment two-way repeated measures ANOVA revealed significant effects of day $\left[\mathrm{F}_{(4,72)}=2.976, \mathrm{p}<0.05\right]$, dose $\left[\mathrm{F}_{(2,18)}=10.155\right.$, $\mathrm{p}<0.01]$, and interaction between factors $\left[\mathrm{F}_{(8,72)}=3.298, \mathrm{p}<0.01\right]$. The post-hoc test revealed a significant decrease in performance in mice treated with $30 \mathrm{mg} / \mathrm{kg}$ of MDMA in comparison with saline treated animals on days 1-2 $(\mathrm{p}<0.05), 3(\mathrm{p}<0.01)$, and 4 $(\mathrm{p}<0.001)$. After treatment withdrawal, two-way ANOVA showed significant effects of day $\left[\mathrm{F}_{(6,108)}=12.191, \mathrm{p}<0.001\right]$, dose $\left[\mathrm{F}_{(2,18)}=11.632 . \mathrm{p}<0.01\right]$, and interaction between factors $\left[\mathrm{F}_{(12,108)}=3.918, \mathrm{p}<0.001\right]$. Mice that had received $30 \mathrm{mg} / \mathrm{kg}$ of MDMA still showed impairments 4 days after drug administration (days 5-7: $\mathrm{p}<0.001$, and 8: $\mathrm{p}<0.05)$, although performance was back to control levels from day 9.

Effects of Repeated MDMA on Saccharine and High-fat Preference and Total Intake

MDMA administration had no significant effects on saccharine preference (Figure 2A) at any dose tested during treatment (effect of day: $F_{(4,84)}=1.333$, NS, dose: $F_{(2,21)}=0.018$, NS, interaction: $F_{(8,84)}=0.711$, NS), or after treatment (effect of day: $\left.F_{(6,126)}=1.544, N S\right]$, dose: $F_{(2,21)}=0.135$, NS, interaction: $F_{(12,126)}=0.857$, NS). 
Mice treated with MDMA at both doses showed a non-significant tendency to decrease high-fat preference during treatment (Figure 2B) (effect of dose: $F_{(2,21)}=3.347$, NS, effect of day: $F_{(4,84)}=4.614, p<0.01$, and interaction: $F_{(8,84)}=1.695$, NS). Following treatment however, the changes induced by MDMA were significant. Thus, two-way repeated measures ANOVA revealed significant effects of day $\left[\mathrm{F}_{(6,126)}=6.896\right.$, $\mathrm{p}<0.001]$, dose $\left[\mathrm{F}_{(2,21)}=5.573, \mathrm{p}<0.05\right]$, and interaction between factors $\left[\mathrm{F}_{(12,126)}=\right.$ 2.425, $\mathrm{p}<0.01]$. A decreased preference for high-fat food was revealed in animals treated with both doses of MDMA (dose of MDMA $3 \mathrm{mg} / \mathrm{kg}$ : days 5 and $6=\mathrm{p}<0.05$; day $7=\mathrm{p}<0.01 ;$ day $8-11=\mathrm{p}<0.05 ;$ dose of $30 \mathrm{mg} / \mathrm{kg}$ : day $5=\mathrm{p}<0.05 ;$ day $7=\mathrm{p}<0.05$; days 9 and $10=\mathrm{p}<0.01$; and day $11=\mathrm{p}<0.05)$.

Total food intake during and after MDMA administration is shown on figure $2 \mathrm{C}$. During treatment, two-way repeated measures ANOVA revealed significant effects of day $\left[\mathrm{F}_{(4,84)}=8.521, \mathrm{p}<0.001\right]$, dose $\left[\mathrm{F}_{(2,21)}=9.331, \mathrm{p}<0.01\right]$, and interaction between factors $\left[\mathrm{F}_{(8,84)}=3.893, \mathrm{p}<0.01\right]$. The post-hoc test revealed a significant decrease in food intake in animals treated with the high dose of MDMA during the entire treatment period (day $1=\mathrm{p}<0.05$; day $2=\mathrm{p}<0.001$; and days $3-4=\mathrm{p}<0.01$ ). However, during post-treatment, although a significant effect of day was revealed $\left[\mathrm{F}_{(6,126)}=3.881\right.$, $\mathrm{p}<0.01]$, no significant effect of dose $\left[\mathrm{F}_{(2,21)}=1.656, \mathrm{NS}\right]$ nor interaction $\left[\mathrm{F}_{(12,126)}=\right.$ $1.343, \mathrm{NS}]$ was observed.

Effects of Repeated MDMA on a Novel Operant Alternation task

Repeated MDMA administration did not impair learning of a novel operant alternation task (Figure 3). The percent of correct trials (accuracy) increased as a function of training day at comparable levels in all groups receiving vehicle or MDMA 
( 3 and $30 \mathrm{mg} / \mathrm{kg}$ ) after drug administration (significant effect of training day: $\mathrm{F}_{(6,102)}=$ 28.686, $\mathrm{p}<0.001)$. No significant effects of dose $\left[\mathrm{F}_{(2,17)}=0.943\right.$, NS $]$ nor interaction between factors was observed $\left[\mathrm{F}_{(12,102)}=0.602, \mathrm{NS}\right]$.

Effects of Repeated MDMA on a Delayed Operant Alternation task

Mice trained for operant alternation and then treated with MDMA were tested on a delayed alternation task (Figure 4A). Two-way repeated measures ANOVA showed a significant main effect of training day $\left[\mathrm{F}_{(6,96)}=13.325, \mathrm{p}<0.001\right]$, no significant effect of dose $\left[\mathrm{F}_{(2,16)}=0.524, \mathrm{NS}\right]$, and a significant interaction between factors $\left[\mathrm{F}_{(12,96)}=2.176\right.$, $\mathrm{p}<0.05]$. The post-hoc test revealed a significant increase in performance in animals treated with the high dose of MDMA (30 mg/kg) on the first day of training (one day after the drug administration) $(\mathrm{p}<0.001)$. In order to evaluate whether MDMA administration induced a general decrease in reaction time on this day; we compared the latency for the first response between groups (Figure 4B). One-way ANOVA showed a significant effect of treatment $\left[\mathrm{F}_{(2,18)}=5.978, \mathrm{p}<0.05\right]$, and the post-hoc test revealed a significant increase in latency in animals treated with $30 \mathrm{mg} / \mathrm{kg}$ of MDMA in comparison with the saline treated group $(\mathrm{p}<0.01)$.

Effects of Repeated MDMA on Visual-cue Discrimination Recall and Set-Shifting Performance

Baseline performance and recall of a visual-cue discrimination task following repeated MDMA administration is shown on figure 5A. A significant main effect of treatment was observed on the first recall session $\left[\mathrm{F}_{(2,21)}=4.540, \mathrm{p}<0.05\right]$, one day after 
treatment. Recall impairments were observed with $30 \mathrm{mg} / \mathrm{kg}$ of MDMA $(\mathrm{p}<0.05)$ as compared to saline on this day, but not on the second recall session $\left[\mathrm{F}_{(2,21)}=2.433\right.$, NS $]$. In the set-shifting task (Figure 5B), mice had to shift from a "respond to cue-light strategy" to a "respond to a position strategy": press the left or right lever irrespective of whether the cue-light was above it or not. One-way ANOVA revealed a main effect of treatment $\left[\mathrm{F}_{(2,21)}=3.594, \mathrm{p}<0.05\right]$ on perseveration errors, but not on never reinforced errors $\left[\mathrm{F}_{(2,21)}=0.724, \mathrm{NS}\right]$. The post-hoc test showed that the number of perseverative errors was significantly increased in mice treated with $30 \mathrm{mg} / \mathrm{kg}$ of MDMA with respect to saline-treated mice $(\mathrm{p}<0.05)$.

In vivo Microdialysis

One day after repeated drug administration, basal extracellular levels of DA in the striatum were not significantly different between groups: saline administration (7.36 $\pm 1.25 \mathrm{pg} / 20 \mu \mathrm{l})$, MDMA $3 \mathrm{mg} / \mathrm{kg}(7.59 \pm 1.23 \mathrm{pg} / 20 \mu \mathrm{l})$, and MDMA $30 \mathrm{mg} / \mathrm{kg}(7.86$ $\pm 0.95 \mathrm{pg} / 20 \mu \mathrm{l})$. A challenge injection of MDMA (10 mg/kg, i.p.) increased DA outflow in the striatum with respect to baseline in mice previously treated repeatedly with saline and with MDMA $3 \mathrm{mg} / \mathrm{kg}$, but not in those previously receiving MDMA 30 $\mathrm{mg} / \mathrm{kg}$ (Figure 4A). Repeated measures ANOVA showed a significant main effect of time $\left[\mathrm{F}_{(5,55)}=4.786, \mathrm{p}<0.01\right]$, dose $\left[\mathrm{F}_{(2,11)}=6.147, \mathrm{p}<0.05\right]$, and a significant interaction between factors $\left[\mathrm{F}_{(10,55)}=3.327, \mathrm{p}<0.01\right]$. Post-hoc analysis comparing pre-treatment at each time point after MDMA acute challenge showed significant differences between saline and $30 \mathrm{mg} / \mathrm{kg}$ of MDMA from 20 to $60 \mathrm{~min}$ after MDMA challenge $(\mathrm{p}<0.01$ $0.001)$. 
Extracellular levels of DA were evaluated in the striatum seven days after repeated drug administration in different groups of mice. Basal extracellular levels of DA in the striatum were not significantly different between groups: saline administration $(5.92 \pm 0.82 \mathrm{pg} / 20 \mu \mathrm{l})$, MDMA $3 \mathrm{mg} / \mathrm{kg}(5.60 \pm 1.18 \mathrm{pg} / 20 \mu \mathrm{l})$, and MDMA $30 \mathrm{mg} / \mathrm{kg}(6.63 \pm 1.20 \mathrm{pg} / 20 \mu \mathrm{l})$. A challenge injection of MDMA (10 mg/kg, i.p.) similarly increased DA levels in the striatum with respect to baseline in all groups (Figure 4C). Thus, repeated measures ANOVA showed a significant main effect of time $\left[\mathrm{F}_{(5,75)}=6.753, \mathrm{p}<0.01\right]$, but no significant effect of dose nor interaction between factors. 


\section{Discussion}

This study shows that a repeated high dose of MDMA induces persistent impairments in recall of operant alternation behaviour and increases perseveration errors in a set-shifting task, suggesting alterations in memory processing and reduced behavioural flexibility. Moreover, this treatment blunts the ability of a subsequent MDMA challenge to increase striatal DA indicating reduced dopamine transporter (DAT) functioning and possible neurotoxic effects.

Mice trained in an operant alternation task were treated twice daily with MDMA ( 3 or $30 \mathrm{mg} / \mathrm{kg}$ ) during 4 days, and tested for recall of the task on the morning after each drug administration. The highest dose of MDMA progressively impaired recall of this acquired behaviour, in line with previous data showing detriments in memory functions in other behavioural paradigms after acute MDMA in mice (Glennon et al. 1987; Trigo et al., 2008), rats (Able et al. 2006) and monkeys (Taffe et al. 2001; Frederick and Paule 1997). The deficits we observed were still apparent after treatment had been discontinued, although levels of responding were back to normal after 5 days of retraining. Our microdialysis data closely paralleled the behavioural changes and showed a time-locked transient reduction in DAT functional activity in the striatum of mice treated with the highest dose of MDMA. Thus, these transient neurochemical changes produced in the striatum could mediate the behavioural alterations observed.

In agreement, neurotoxic doses of MDMA have been shown to produce temporary decreases in striatal DAT binding in mice studies using receptor autoradiography (Trigo et al., 2008; Plaza-Zabala et al., 2010), or immunohistochemitry (Granado et al., 2008) techniques. The recovery of striatal DAT after MDMA was attributed to compensatory sprouting or branching of dopaminergic nerve fibres (Granado et al., 2008), or to transient MDMA-induced regulation of DAT cell surface 
expression (Jayanthi and Ramamoorthy, 2005). There is evidence supporting the involvement of the mesostriatal dopamine system in habit formation/instrumental conditioning (Faure et al. 2005), and the functional interaction between the caudate nucleus and the prefrontal cortex (PFC) is crucial for acquired learning (Histed et al., 2009). Thus, our studies substantiate previous findings and suggest that MDMAinduced decreases in DAT functionality in the striatum of mice may be related to memory and recall impairments.

In contrast, no changes in basal DA levels were observed in MDMA-treated mice with respect to controls. This lack of effect could be explained by the presence of compensatory mechanisms following MDMA-induced disruptions in DAT activity. A similar situation has been observed with respect to 5-HT in rats following MDMA exposure. Thus, while tissue 5-HT content (Capela et al., 2009), and MDMA-evoked increases in 5-HT overflow (Shankaran and Gudelsky, 1999) were reduced, no changes in basal extracellular 5-HT levels were revealed (Gartside, McQuade, Sharp, 1996).

The possibility that the deficits observed were due to an anhedonic state, reducing the motivation of mice to perform the operant task was ruled out in parallel behavioural studies. Thus, no changes in saccharin preference were observed either during the 4 days of treatment or the following 7 drug-free days with respect to control mice treated with saline. Changes in locomotor activity produced by the high dose of MDMA, including hyperlocomotion or decreased locomotion due to stereotypic movements, were also unlikely to have contributed to the deficit in alternation observed since animals were tested $19 \mathrm{~h}$ after drug administration without the drug on board.

On the other hand, both doses of MDMA (3 and $30 \mathrm{mg} / \mathrm{kg}$ ) reduced preference for a high-fat diet during and after treatment, while total caloric intake was reduced by the highest dose of MDMA only during MDMA administration. This effect may be due 
to the anorectic properties of MDMA mediated by increased 5-HT and DA release in brain areas related to feeding behaviour. Alternatively, this effect may be indirectly related to MDMA-induced hyperthermia and its modulation of fat intake. In this sense, studies in rats have shown a reciprocal effect of dietary fats on MDMA-induced hyperthermia. Thus, high-fat fed rats receiving MDMA show greater hyperthermia than low-fat fed rats (Mills et al., 2007).

Contrary to these effects produced when MDMA was administered during the acquisition period, mice pre-treated repeatedly with MDMA showed normal acquisition of the operant alternation task, reaching criteria in the same number of training days than controls. These results suggest that pre-treatment with even high doses of MDMA do not impair learning positive reinforced operant tasks involving short-term memory. In contrast, it has been previously shown that repeated pre-treatment with a high dose regimen of MDMA reduces the acquisition of active avoidance (Trigo et al., 2008), a more complex behaviour entailing classical conditioning and aversive reinforcement.

The effects of repeated MDMA on the acquisition of a delayed alternation task were also evaluated in mice previously trained to perform operant alternation with no delays. These experimental conditions assured a specific effect on behavioural inhibition without a possible confounding effect on alternation. In this paradigm, which assesses central inhibitory processes related to impulsivity and to medial PFC functionality (Granon et al., 1994; Goldman-Rakic, 1995), mice must inhibit responding for a period of time in order to receive a reward. Under these conditions, the group pretreated with the highest dose of MDMA performed better than controls. However, this amelioration was only observed on the first day of testing, and was probably due to decreased reaction time since mice were slower than controls in making the first response to begin the session. On subsequent days, no differences in performance were 
apparent between MDMA- and saline-treated mice. This suggests that the neuronal adaptations taking place after this high dose regimen of MDMA, including decreased DAT functionality in the striatum may not interfere with inhibitory control under these experimental conditions. In agreement, the relationship between impulsivity and MDMA in humans has been difficult to establish with some studies showing increased impulsivity in MDMA users (Morgan 1998), while others report no differences from control subjects (Fox et al. 2002). Another possibility for the lack of effect in our study is that the attentional workload of the delays used in this task was too low to reveal any impairment. Accordingly, MDMA administration in rats produces persistent deficits in a delayed non-match-to performance (DNMTP) procedure when longer delays intervals (30 s) are employed (Marston et al., 1999). However, for technical reasons, these long delays cannot be used in the delayed alternation task in mice (Weiss et al., 2005).

The high dose of MDMA also impaired visual-cue discrimination recall, although this effect was transient with mice showing baseline performance on the second retraining session. More importantly, MDMA increased total errors to criteria in the set-shifting task with respect to control mice treated with saline. This effect was mostly due to an increase in perseveration errors, while "never-reinforced" errors were not affected. Thus, treated mice quickly learned the novel strategy, but they continued to respond to a stimulus that no longer produced a reward, demonstrating decreased behavioural flexibility. These results are in line with human data showing that subjects with a history of MDMA use perform worse on cognitive tasks related to behavioural flexibility and show more perseverative behaviours (von Geusau et al., 2004). However, other data show no deficits in attentional set-shifting in human MDMA users (Fox et al., 2001). The formation of attentional sets, and the ability to shift from one strategy to another have been related to mesocortical DA function in several different animal 
species (Roberts et al, 1994; Floresco et al, 2006), while PFC 5-HT systems have been involved in other types of behavioural flexibility such as reversal learning (Clarke et al, 2005). In line with the data showing the involvement of PFC DA in set-shifting, it has been shown that repeated amphetamine administration in rats induces impairments in extradimensional set-shifting, which was attenuated by direct infusion of a D1 agonist into the PFC (Fletcher et al, 2005). In addition, rats with a history of methamphetamine self-administration showed selective impairments in a set-shifting task and associated changes in dopaminergic neural activity in the PFC (Parsegian et al., 2011). Our neurochemical data in mice show an MDMA-induced dysregulation in striatal DAT functioning, suggesting that alterations in striatal DA could also promote behavioural inflexibility. Likewise, Parkinsonian patients in the early stages of the disease, when dopaminergic deficits are mostly restricted to the rostrodorsal portion of the caudate nucleus, are impaired in extradimensional set-shifting (Monchi et al., 2007). Thus, our results corroborate converging data showing that the functional interaction between the striatum and the PFC is required for optimal executive functioning and that striatal DA modulates this association (Nagano-Saito et al., 2008).

In summary, our study shows that neurotoxic doses of MDMA producing transient changes in DAT functionality in mice are associated with temporary impairments in memory and recall of operant alternation. Moreover, these alterations in striatal dopamine activity may also contribute to inflexible responding in a set-shifting task. 


\section{Author Contributions}

$\mathrm{XV}, \mathrm{PR}$ and $\mathrm{RM}$ conceived and designed the study. $\mathrm{XV}$ and PR contributed to the acquisition of animal data. XV, PR and RM assisted with data analysis and interpretation of findings. All authors contributed to and have approved the final manuscript.

\section{Acknowledgments}

The authors acknowledge Ms. Dulce Real for her valuable contribution in the microdialysis-HPLC experiments. This work was supported by the DG Research of the European Commission (PHECOMP: LHSM-CT-2007-037669), the Spanish "Instituto de Salud Carlos III" (RD06/001/001 and PI070709), FEDER funds, and "Ministerio de Ciencia e Innovación" (SAF2007-64062), the Catalan Government (SGR2009-00131) and the ICREA Foundation (ICREA Academia-2008). 


\section{References}

1. Able JA, Gudelsky GA, Vorhees CV, Williams MT (2006) 3,4Methylenedioxymethamphetamine in adult rats produces deficits in path integration and spatial reference memory. Biol Psychiatry 59:1219-1226.

2. Bhattachary S, Powell JH (2001) Recreational use of 3,4methylenedioxymethamphetamine (MDMA) or 'ecstasy': evidence for cognitive impairment. Psychol Med 31(4):647-58.

3. Capela JP, Carmo H, Remião F, Bastos ML, Meisel A, Carvalho F (2009) Molecular and cellular mechanisms of ecstasy-induced neurotoxicity: an overview. Mol Neurobiol 39(3):210-71.

4. Clark L, Roiser JP, Robbins TW, Sahakian BJ (2009) Disrupted 'reflection' impulsivity in cannabis users but not current or former ecstasy users. J Psychopharmacol 23(1):14-22.

5. Clarke HF, Walker SC, Crofts HS, Dalley JW, Robbins TW, Roberts AC (2005). Prefrontal serotonin depletion affects reversal learning but not attentional set shifting. J Neurosci 25(2):532-8.

6. Colado MI, O'Shea E, Green AR. Acute and long-term effects of MDMA on cerebral dopamine biochemistry and function (2004). Psychopharmacology (Berl) 173(3-4):249-63.

7. Dafters RI (2006) Impulsivity, inhibition and negative priming in ecstasy users. Addict Behav 31(8):1436-41.

8. Dalley JW, Lääne K, Theobald DE, Peña Y, Bruce CC, Huszar AC, Wojcieszek M, Everitt BJ, Robbins TW (2007) Enduring deficits in sustained visual attention during withdrawal of intravenous methylenedioxymethamphetamine self-administration in rats: results from a comparative study with d-amphetamine and methamphetamine. Neuropsychopharmacology 32(5):1195-206. 
9. de Sola Llopis S, Miguelez-Pan M, Peña-Casanova J, Poudevida S, Farré M, Pacifici R, Böhm P, Abanades S, Verdejo García A, Langohr K, Zuccaro P, de la Torre R (2008) Cognitive performance in recreational ecstasy poly-drug users: a two-year follow-up study. J Psychopharmacol 22: 498-510.

10. Enomoto T, Tse MT, Floresco SB (2011) Reducing prefrontal gammaaminobutyric acid activity induces cognitive, behavioral, and dopaminergic abnormalities that resemble schizophrenia. Biol Psychiatry 69(5):432-41.

11. Faure A, Haberland U, Condé F, El Massioui N (2005) Lesion to the nigrostriatal dopamine system disrupts stimulus-response habit formation. J. Neurosci 25:2771-2780.

12. Fletcher PJ, Tenn CC, Rizos Z, Lovic V, Kapur S (2005) Sensitization to amphetamine, but not PCP, impairs attentional set shifting: reversal by a D1 receptor agonist injected into the medial prefrontal cortex. Psychopharmacology (Berl) 183(2):190-200.

13. Floresco SB, Magyar O, Ghods-Sharifi S, Vexelman C, Tse MT (2006) Multiple dopamine receptor subtypes in the medial prefrontal cortex of the rat regulate set-shifting. Neuropsychopharmacology 31: 297-309.

14. Fox HC, Parrott AC, Turner JJ (2001) Ecstasy use: cognitive deficits related to dosage rather than self-reported problematic use of the drug. J Psychopharmacol 15(4):273-81. 
15. Fox HC, McLean A, Turner JJ, Parrott AC, Rogers R, Sahakian BJ (2002) Neuropsychological evidence of a relatively selective profile of temporal dysfunction in drug-free MDMA ("ecstasy") polydrug users. Psychopharmacology (Berl) 162(2):203-14.

16. Frederick DL, Paule MG (1997) Effects of MDMA on complex brain function in laboratory animals.Neurosci Biobehav Rev 21(1):67-78.

17. Gartside SE, McQuade R, Sharp T (1996) Effects of repeated administration of 3,4-methylenedioxymethamphetamine on 5-hydroxytryptamine neuronal activity and release in the rat brain in vivo. J Pharmacol Exp Ther 279(1):277-83.

18. Goldman-Rakic PS (1995) Cellular basis of working memory. Neuron. 14(3):477- 485 .

19. Glennon RA, Little PJ, Rosecrans JA, Yousif M (1987) The effect of MDMA ("Ecstasy") and its optical isomers on schedule-controlled responding in mice. Pharmacol Biochem Behav 26:425-426

20. Gouzoulis-Mayfrank E, Daumann J (2006) The confounding problem of polydrug use in recreational ecstasy/MDMA users: a brief overview. J Psychopharmacol 20(2):188-93.

21. Granado N, O'Shea E, Bove J, Vila M, Colado MI, Moratalla R (2008b) Persistent MDMA-induced dopaminergic neurotoxicity in the striatum and substantia nigra of mice. J Neurochem 107(4):1102-12.

22. Granon S, Vidal C, Thinus-Blanc C, Changeux J-P, Poucet B (1994) Working memory, response selection and effortful processing in rats with medial prefrontal lesions. Behav Neurosci 108(5):883- 891.

23. Hanson KL, Luciana M (2010) Neurocognitive impairments in MDMA and other drug users: MDMA alone may not be a cognitive risk factor. J Clin Exp Neuropsychol 32(4):337-49. 
24. Hanson KL, Luciana M, Sullwold K (2008) Reward-related decision-making deficits and elevated impulsivity among MDMA and other drug users. Drug Alcohol Depend 96(1-2):99-110.

25. Histed MH, Pasupathy A, Miller EK (2009) Learning substrates in the primate prefrontal cortex and striatum: sustained activity related to successful actions. Neuron 63(2):244-53.

26. Jayanthi LD, Ramamoorthy S (2005) Regulation of monoamine transporters: influence of psychostimulants and therapeutic antidepressants. AAPS J 7(3):E728-38.

27. Kalechstein AD, De La Garza R, Mahoney JJ, Fantegrossi WE, Newton TF (2007) MDMA use and neurocognition: a meta-analytic review. Psychopharmacology (Berl) 189(4):531-7.

28. Koob GF, Volkow ND (2010) Neurocircuitry of addiction. Neuropsychopharmacology 35(1):217-38.

29. Marston HM, Reid ME, Lawrence JA, Olverman HJ, Butcher SP (1999) Behavioural analysis of the acute and chronic effects of MDMA treatment in the rat. Psychopharmacology (Berl) 144(1):67-76.

30. Mayerhofer A, Kovar KA, Schmidt WJ (2001) Changes in serotonin, dopamine and noradrenaline levels in striatum and nucleus accumbens after repeated administration of the abused drug MDMA in rats. Neurosci Lett 308(2):99-102.

31. Mills EM, Weaver KL, Abramson E, Pfeiffer M, Sprague JE (2007) Influence of dietary fats on Ecstasy-induced hyperthermia. Br J Pharmacol 151(7):1103-8. 
32. Monchi O, Petrides M, Mejia-Constain B, Strafella AP (2007) Cortical activity in Parkinson's disease during executive processing depends on striatal involvement. Brain 130:233-44.

33. Morgan MJ (1998) Recreational use of "ecstasy" (MDMA) is associated with elevated impulsivity. Neuropsychopharmacology 19(4):252-64.

34. Nagano-Saito A, Leyton M, Monchi O, Goldberg YK, He Y, Dagher A (2008) Dopamine depletion impairs frontostriatal functional connectivity during a setshifting task. J Neurosci 28(14):3697-706.

35. Parsegian A, Glen WB Jr, Lavin A, See RE (2011) Methamphetamine selfadministration produces attentional set-shifting deficits and alters prefrontal cortical neurophysiology in rats. Biol Psychiatry 69(3):253-9.

36. Paxinos G, Franklin KBJ (1997) The mouse brain in stereotaxic coordinates. Academic, San Diego

37. Plaza-Zabala A, Viñals X, Maldonado R, Robledo P (2010) Effects of repeated MDMA administration on the motivation for palatable food and extinction of operant responding in mice. Psychopharmacology (Berl) 208(4):563-73.

38. Quednow BB, Kühn KU, Hoppe C, Westheide J, Maier W, Daum I, Wagner M (2007) Elevated impulsivity and impaired decision-making cognition in heavy users of MDMA ("Ecstasy"). Psychopharmacology (Berl) 189(4):517-30.

39. Ricaurte GA, Forno LS, Wilson MA, DeLanney LE, Irwin I, Molliver ME, Langston JW (1988) (+/-)3,4-Methylenedioxymethamphetamine selectively damages central serotonergic neurons in nonhuman primates. JAMA 260(1):515 . 
40. Roberts AC, De Salvia MA, Wilkinson LS, Collins P, Muir JL, Everitt BJ, Robbins TW (1994) 6-Hydroxydopamine lesions of the prefrontal cortex in monkeys enhance performance on an analog of the wisconsin card sort test: possible interactions with subcortical dopamine. J Neurosci 14:2531-2544.

41. Robledo P, Mendizabal V, Ortuño J, de la Torre R, Kieffer BL, Maldonado R (2004) The rewarding properties of MDMA are preserved in mice lacking muopioid receptors. Eur J Neurosci 20(3):853-8.

42. Schenk S, Harper DN, Do J (2010) Novel object recognition memory: measurement issues and effects of MDMA self-administration following short inter-trial intervals. J Psychopharmacol [Epub ahead of print] PMID:21148025

43. Shankaran M, Gudelsky GA (1999) A neurotoxic regimen of MDMA suppresses behavioral, thermal and neurochemical responses to subsequent MDMA administration. Psychopharmacology (Berl) 147(1):66-72.

44. Taffe MA, Weed MR, Davis S, Huitrón-Resendiz S, Schroeder R, Parsons LH, Henriksen SJ, Gold LH (2001) Functional consequences of repeated (+/-)3,4methylenedioxymethamphetamine (MDMA) treatment in rhesus monkeys. Neuropsychopharmacology 24(3):230-9.

45. Trigo JM, Cabrero-Castel A, Berrendero F, Maldonado R, Robledo P (2008) MDMA modifies active avoidance learning and recall in mice. Psychopharmacology (Berl) 197(3):391-400.

46. Verdejo-García AJ, López-Torrecillas F, Aguilar de Arcos F, Pérez-García M (2005) Differential effects of MDMA, cocaine, and cannabis use severity on distinctive components of the executive functions in polysubstance users: a multiple regression analysis. Addict Behav 30(1):89-101.

47. von Geusau NA, Stalenhoef P, Huizinga M, Snel J, Ridderinkhof KR (2004) Impaired executive function in male MDMA ("ecstasy") users. Psychopharmacology (Berl) 175(3):331-41. 
48. Wareing M, Fisk JE, Murphy P, Montgomery C (2004) Verbal working memory deficits in current and previous users of MDMA. Hum Psychopharmacol 19(4):225-34.

49. Weiss B, Stern S, Cox C, Balys M (2005) Perinatal and lifetime exposure to methylmercury in the mouse: behavioral effects. NeuroToxicology 26(4):675690.

50. Winstanley CA, Olausson P, Taylor JR, Jentsch JD (2010) Insight into the relationship between impulsivity and substance abuse from studies using animal models. Alcohol Clin Exp Res 34(8):1306-18. 


\section{Figure Legends}

Figure 1. Operant alternation behaviour in mice achieving criteria before treatment (BL), during the 4 days of treatment with MDMA (3 mg/kg, $\mathrm{n}=7 ; 30 \mathrm{mg} / \mathrm{kg}, \mathrm{n}=7)$ and saline $(n=7)$, and during 7 days post-treatment. The data represent the mean ratio of correct responses \pm SEM. $* \mathrm{p}<0.05 ; * * \mathrm{p}<0.01 ; * * * \mathrm{p}<0.001$ vs. saline treated animals (Dunnet post-hoc test).

Figure 2. Saccharine preference (A) (\% of total fluid intake) in mice before treatment (BL), during the 4 days of treatment with saline $(\mathrm{n}=8), 3 \mathrm{mg} / \mathrm{kg}(\mathrm{n}=8)$ and $30 \mathrm{mg} / \mathrm{kg}$ of MDMA ( $\mathrm{n}=8)$, and during 7 days post-treatment. High-fat food preference (B) (\% of total food intake) in mice before treatment (BL), during the 4 days of treatment with saline $(\mathrm{n}=8), 3 \mathrm{mg} / \mathrm{kg}(\mathrm{n}=8)$ and $30 \mathrm{mg} / \mathrm{kg}$ of MDMA $(\mathrm{n}=8)$, and during 7 days posttreatment. Caloric Intake (C) (Kcal) in mice before treatment (BL), during the 4 days of treatment with saline $(\mathrm{n}=8), 3 \mathrm{mg} / \mathrm{kg}(\mathrm{n}=8)$ and $30 \mathrm{mg} / \mathrm{kg}$ of MDMA $(\mathrm{n}=8)$, and during 7 days post-treatment. The data represent mean \pm SEM. $* \mathrm{p}<0.05 ; * * \mathrm{p}<0.01$; *** $\mathrm{p}<0.001(30 \mathrm{mg} / \mathrm{kg}$ vs. saline $)$, ts $\mathrm{p}<0.05$, 必文 $\mathrm{p}<0.01(3 \mathrm{mg} / \mathrm{kg}$ vs saline $)$ (Dunnet post-hoc test).

Figure 3. Operant alternation behaviour in mice following treatment with MDMA and saline twice a day during 4 days (saline, $\mathrm{n}=7 ; 3 \mathrm{mg} / \mathrm{kg}$ of MDMA, $\mathrm{n}=7 ; 30 \mathrm{mg} / \mathrm{kg}$; $\mathrm{n}$ $=6$ ). The data represent the mean ratio of correct responses \pm SEM.

Figure 4. Acquisition of operant delayed alternation (A) in trained mice (BL) one day after treatment with MDMA $(3 \mathrm{mg} / \mathrm{kg}, \mathrm{n}=7 ; 30 \mathrm{mg} / \mathrm{kg}, \mathrm{n}=6)$ and saline $(\mathrm{n}=6)$. The data represent the mean ratio of correct responses \pm SEM. (B) Reaction time to produce the first response on the first day of the operant delayed alternation task $(\mathrm{n}=6), 3 \mathrm{mg} / \mathrm{kg}$ 
of MDMA $(n=7)$ or $30 \mathrm{mg} / \mathrm{kg}$ of MDMA $(n=6)$. The data represent the mean latency to response in $\sec \pm$ SEM on day 5. $* * \mathrm{p}<0.01, * * * \mathrm{p}<0.001 \mathrm{vs.}$ saline treated animals (Dunnet post-hoc test).

Figure 5. Visual-cue discrimination (A) in mice trained to criteria (BL), and during 2 consecutive recall sessions following treatment with saline $(\mathrm{n}=6), 3 \mathrm{mg} / \mathrm{kg}$ of MDMA $(\mathrm{n}=8)$ and $30 \mathrm{mg} / \mathrm{kg}$ of MDMA $(\mathrm{n}=8)$. Recall 1 and Recall 2 were performed one and two days after treatment, respectively. The data represent the mean ratio of correct responses + SEM. $*$ p $<0.05$ vs. saline treated animals (Dunnet post-hoc test). (B) Error by type (Perseveration and Never Reinforced) produced when the task was shifted from a respond-to-cue light strategy to a respond-to-position strategy saline $(\mathrm{n}=6), 3 \mathrm{mg} / \mathrm{kg}$ of MDMA $(n=8)$ or $30 \mathrm{mg} / \mathrm{kg}$ of MDMA $(\mathrm{n}=8)$. The data represent the mean number of errors to criteria + SEM. $* \mathrm{p}<0.05$ vs. saline treated animals (Dunnet post-hoc test).

Figure 6. Dopamine (DA) outflow in the striatum (mean + SEM \% of baseline) of mice previously treated with MDMA ( 3 and $30 \mathrm{mg} / \mathrm{kg}$ ) and saline twice a day for 4 days. One day after treatment (day 5) (A), an acute challenge with MDMA (10 mg/kg; arrow) increased DA outflow in mice treated with saline $(\mathrm{n}=7)$ and $3 \mathrm{mg} / \mathrm{kg}(\mathrm{n}=5)$, but not in those treated with $30 \mathrm{mg} / \mathrm{kg}(\mathrm{n}=7)$. Significant differences between the $30 \mathrm{mg} / \mathrm{kg}$ treatment group and controls were observed from 20 to 60 min after drug challenge $(* *$ $\mathrm{p}<0.01, * * * \mathrm{p}<0.001$, Dunnett post-hoc test). Seven days after the last drug administration (day 11), an acute challenge with MDMA (10 mg/kg; arrow) increased DA outflow (B) in mice treated with saline $(\mathrm{n}=7), 3 \mathrm{mg} / \mathrm{kg}(\mathrm{n}=6)$ and $30 \mathrm{mg} / \mathrm{kg}(\mathrm{n}=$ 8). 